\title{
Autism, schizofrenie, ADHD. Perspective convergente
}

\section{Bogdana MICLEA ${ }^{1}$}

\begin{abstract}
Over time, continuous efforts have been made to clarify and circumscribe diagnoses of autism, schizophrenia, and attention deficit hyperactivity disorder (ADHD). The diagnostic split between the 3 disorders dominated psychiatry after the 80 s, being still used and recognized as such by the diagnostic manuals. Recently a shift and flexibility of the psychiatric paradigm has been noticed. The categorical perspective on mental illness is gradually complemented by the dimensional one. In the last decade, research in the field of neuroscience and psychology has brought evidence in favor of a partial overlap between ADHD, autism and schizophrenia. The hypothesis of a partial overlap can also be supported by non-medical or psychological theorizations, related to common deficits of symbolic structuring of the psyche in achieving a coherent representation of the world and of one's own person.
\end{abstract}

Keywords: autism, schizophrenia, ADHD, diagnosis, partial overlap

Sistemele de clasificare elaborate de Organizația Mondială a Sănătății (OMS) și Asociația Psihiatrică Americană (APA) au recurs la o modalitate de clasificare predominant epidemiologică, ceea ce a modelat înțelegerea bolilor psihice pe criterii mai degrabă statistice și descriptive după anii 19501. Autismul, schizofrenia și tulburarea de hiperactivitate cu deficit atențional (ADHD), sunt considerate în prezent categorii diagnostice distincte, ceea ce implică tratament farmacologic și psihologic specific însă de-a lungul timpului, s-au făcut eforturi continue de a clarifica și circumscrie cele 3 diagnostice.

\section{Autismu!}

Autismul considerat acum o tulburare de neurodezvoltare, a fost înțeles inițial ca o formă de psihoză infantilă, însuși termenul "autistic" fiind preluat de la Bleuler (1911) care îl utiliza pentru a descrie manifestări ale schizofreniei. Mai târziu, psihologii și psihiatrii europeni - în mod particular cei britanici și cei americani au revizuit conceptul inițial de psihoză infantilă și au clasificat autismul ca distinct de schizofrenie asociindu-l $\mathrm{cu}$ întârzierea mintală și alte anomalii de dezvoltare psihică a copiilor. Ulterior a fost considerat o tulburare de comunicare. În 1980 autismul a fost inclus separat în DSM III, în randul tulburărilor pervazive de dezvoltare ale copilăriei și totodată s-au eliminat simptomele autiste din descrierea schizofreniei adultului (prezente în DSM II)2. Pentru încadrarea diagnostică s-a recurs la criterii descriptive behavioriste și ulterior cognitiviste, au persistat însă dificultățile de conturare a unui tablou psiho-patologic stabil și de identificare a unor cauze specifice. Aceste variații în prezentarea clinică în care există totuși un set central de alterări, stabil de-a lungul vieții, a condus la lărgirea fenotipului autist (McPartland, J., \& Volkmar, F. R. 2012). Din aceste motive în DSM V s-a adoptat denumirea de Tulburare de Spectru Autist (TSA) care cuprinde tablouri clinice variate având ca elemente comune: disfuncția socială, comunicarea deviantă, comportamentele neobișnuite sau bizare, etiologia fiind una neurocognitivă. 


\section{Schizofrenia}

Schizofrenia (SCZ) rămâne o afecțiune incomplet cunoscută, considerată a avea o etiologie mixtă genetică și psiho-socială, care destructurează persoana și îi afectează extensiv funcționarea. Schizofrenia copilului este o tulburare rar raporatată prepubertar (sub 1/10 ooo copii) iar în numeroase cazuri a fost observată comorbidatea cu tulburări de neurodezvoltare cum ar fi dizabilitatea intelectuală sau autismul. În adolescență și la adulții tineri incidența schizofreniei crește semnificativ ( $1 / 500$ tineri de 18 ani). În majoritatea cazurilor nu s-au identificat elemente clare în copilărie prin care s-ar putea anticipa debutul ulterior al psihozei însă s-a delimitat o categorie de copii și tineri cu risc foarte înalt de a dezvolta schizofrenie. Aceștia prezintă o asociere de factori: personalitate schizotipală, antecedente familiale de schizofrenie, simptome psihotice tranzitorii, subclinice și declin funcțional. Identificarea acestor persoane cu risc ridicat de boală și intervenția terapeutică precoce este esențială în vederea reducerii riscului debutului psihozei clinice (IACAPA). Similar autismului, heterogenitatea tabloului clinic a impus lărgirea conceptului iar în prezent vorbim de tulburări din spectrul schizofreniei.

\section{ADHD}

Manifestări similare celor incluse actual în tulburarea de hiperactivitate cu deficit atențional au fost descrise deja din 1798 de Crichton totuși conceptul modern al acestei afecțiuni este de dată relativ recentă. Tulburarea de hiperactivitate cu deficit atențional - ADHD - este considerată în prezent o afecțiune cu o componenentă ereditară importantă $\begin{array}{lcr}\text { caracterizată } & \text { prîntr-o } & \text { disfuncție } \\ \text { neuropsihologică } & \text { a } & \text { inhibiției } \\ \text { comportamentale } & - & \text { componentă } \quad \text { a }\end{array}$ funcțiilor executive implicând și memoria de lucru5. Denumirea de ADHD a fost recent introdusă în ICD 11. ICD 10 includea o categorie diagnostică similară numită tulburare hiperkinetica - HKD - cu o subcategorie în care era menționată afectarea concomitentă a atentiei. DSM IV-TR adoptase deja aceasta formulare de ADHD. Până relativ recent, autismul și ADHD erau menționate în secțiuni de psiho-patologie aflate la distanță - deși s-a observat că un procent ridicat de copii prezintă simptome din ambele afecțiuni devreme în dezvoltare - însă în DSM V și ICD 11 cele două sunt incluse în cadrul Tulburărilor de neurodezvoltare sugerându-se existența unor deficite centrale similare și a unui continuum între ADHD și autism.

Se remarcă faptul că în timp, conceptualizarea celor 3 afecțiuni s-a modificat iar separarea clară între autism, schizofrenie și ADHD precum și necesitatea încadrării manifestărilor de tip hiperactivitate și neatenție într-o categorie diagnostică suplimentară - în cazul copiilor cu autism - nu este întotdeauna ușor de justificat. Pentru psihiatrii care iau pentru prima dată în evidență un pacient adult este adesea dificil să facă din punct de vedere clinic o diferență clară între autism și schizofrenie sau o tulburare de personalitate schizotipala iar în mediul clinic al practicii cotidiene s-a menținut observația că autismul "evoluează într-o manieră asemănătoare schizofreniei” (Dobreascu, 2016) . 
Scindarea diagnostică menționată a dominat psihiatria de după anii 8o, fiind încă utilizată și recunoscută ca atare de manualele de diagnostic OMS și APA. Recent se observă o nuanțare și flexibilizare a paradigmei psihiatrice, care anunță o posibilă schimbare. Perspectiva categorială asupra maladiilor psihice menținută datorită nevoii de omogenitate, precizie și claritate în cercetare și clinică este treptat completată cu cea dimensională care admite necesitatea recunoașterii unei suprapuneri parțiale între patologii și între boală și normalitate. În plus maladiile sunt abordate de noile manuale de diagnostic în perspectivă developmentală, adică grupate corelat cu poziția lor în cursul dezvoltării unei persoane, având implicații în evoluția globală a unui individ în plan psihic. Pe această linie de conceptualizare, tulburările din spectrul schizofreniei sunt descrise imediat după cele de neurodezvoltare. Între aceste "spectre" ale autismului și schizofreniei distanța s-a redus iar ADHD este și el regăsit mai apropiat de TSA, în aceeasi grupă de tulburări de neurodezvoltare și nu mai este descris alături de tulburările de comportament (APA, 2013) .

La această reorientare a paradigmei stiințifice privind patologia psihică, au contribuit în ultima decadă cercetări din domeniul neuroștiințelor și a psihologiei. Acestea au adus evidențe în favoarea unei parțiale suprapuneri între ADHD, autism și schizofrenie iar alte afecțiuni ca tulburarea afectivă bipolară, dizabilitatea intelectuală și depresia sunt și ele vizate de cercetători.

Un studiu genetic recent (Olafur O Gudmundson, 2019) indică faptul că
ADHD, autismul și schizofrenia impărtășesc aceleași alele CNV (copy number variations - variațiile numărului de copii, adică pentru același locus perechile de baze care alcătuiesc materialul genetic au aceeași structură repetiții sau deleții).

Un alt studiu din 2017 care a inclus peste 33 ooo de cazuri și aproape 28 ooo de persoane în grupul de control arată că există un grad semnificativ de suprapunere genetică între ADHD, autism, schizofrenie, dizabilitate intelectuală, tulburare afectivă bipolară, tulburare depresivă majoră și tulburare de personalitate antisocială (Huiying Zhao, 2017) la nivelul SNP (single nucleotide polymorphism - substituție a unei singure nucletotide într-o poziție specifică a genomului ceea ce duce la existența mai multor alele)

Multe alte studii GWAS (genome-wide association studies) din ultima decadă prin care se cercetează pe cohorte populaționale mari variațiile genetice care ar putea fi asociate cu diverse maladii au subliniat suprapunerea genetică semnificativa între schizofrenie și autism sau între ADHD și autism atât la copii cât și la adulțio(Demontis 2019). S-a propus existența unei constelații poligenice care conduce prin efectul cumulat al SNP, detectată prin analiză GWAS, la risc înalt pentru unele afecțiuni cum ar fi ADHD sau la alte fenotipuri patologice dintre cele menționaten(Middeldorp, 2016). Această perspectivă e în concordanță cu abordarea dimensională a maladiilor psihice în care implicarea variată cantitativ a anumitor caracteristici conturează un profil sau altul de boală și îl face să devină evident clinic, depășind normalitatea 


\section{Conștiințta de sine}

Conștiința de sine este un element cheie al oricărei experiențe conștiente și a reglării comportamentului. Constiința de sine presupune $\mathrm{o}$ autoreferențialitate care însoțeste orice eveniment desfășurat în stare de veghe (trezire fenomenologică). Conștiința anoetică este prezentă înainte de dezvoltarea limbajului și presupune un flux perceptiv-afectiv fundamental care se traduce prin impresia că ceva este trăit la persoana I. Gradual se dezvoltă constiința noetică bazată pe cunoaștere și concepte. Aceasta va evolua și se va remania apoi în cursul vieții încorporând o gamă tot mai variată de experiențe implicând invațare dar și amintire și recunoaștere și asigurând astfel o înțelegere coerentă și structurată a lumii, nefracturată de localizarea în timp sau context și permițând proiecția în viitor - constiința autonoetică. Rețele neuronale subcorticale sunt implicate în conștiința anoetică. De buna lor funcționare va depinde dezvoltarea ulterioară a constiinței noetice ce permite învățarea făcând apel la memoria semantică (susținută de structuri cerebrale intermediare cum ar fi ganglionii bazali și zone din cortexul prefrontal și temporal) și autonoetice ce face apel și la memoria episodică și care implică rețele neocorticale de ordin superior. În copilărie, în perioada prelingvistică a existenței umane, lumea este recepționată fără referințe conceptuale, cu o implicare afectiv-corporală predominantă. Ulterior în cursul experiențelor cotidiene ce presupun conștiința noetică și autonoetică explicită va fi implicată și constiința anoetică corelată $\mathrm{cu}$ dimensiunea corporal-afectivă, implicită a fenomenelor. Pe lângă rețelele corticale sunt activate și cele subcorticale iar un proces de sincronizare/desincronizare între procese de activare neuronală de la niveluri diferite se desfășoară în cursul experienței conștiente. $\mathrm{O}$ rețea paralimbică este activă în menținerea conștiinței de sine iar regiunile acestei rețele interacționează prin gama sincronie reglată de dopamină și alți neurotransmițători prin interneuronii de tip GABA. S-a constatat că atât în autism cât și în ADHD și schizofrenie există alterări majore ale funcționării acestei rețeleıı (Hans C Lou, Vandekerckhove 2014)

\section{Cogniția socială.}

Felul în care ne raportăm la ceilalți (teoria minții-ToM) este modificată în autism, schizofrenie și ADHDı3. Mentalizarea este considerată din punct de vedere psihologic o abilitate esențială cogniției și interacțiunii sociale. Adică modul în care vom interacționa cu ceilalți și ne vom raporta la ei este strâns legat de felul în care percepem și interpretăm gesturile, mimica, comportamentul și ceea ce spun ceilalți. În toate cele 3 afecțiuni s-a constatat că există o afectare a cogniției sociale deși sunt descrise caracteristici particulare fiecărei afecțiuni. În schizofrenia cu tablou paranoid studii de rezonanță magnetică funcțională (fMRI) au evidențiat faptul că pacienții prezintă hiperintenționalitate, adică activare a creierului în unele zone atunci când li se prezintă informații care cer mentalizare (atribuire excesivă de intenții în interacțiunea sociala și o dificultate de a discrimina între propriile intenții și reprezentări ale statusului mintal și cele ale altora). Autismul se caracterizează prin hipointenționalitate - Indivizii cu TSA 
prezintă o imposibilitate de "citire a gândurilor" celorlalți, adică au dificultăți în înțelegerea intențiilor celor cu care interacționează, raportându-se la ei mai degrabă obiectual. Hipointenționalitatea din TSA este asociată cu hipoactivare în zone ale creierului care în mod obișnuit sunt corelate cu interacțiunea socială complexă (Ciaramidaro A, 2015). Zonele din creier unde se produce hiper/hipoactivare în SCZ/TSA detectate prin fMRI sunt: Cortexul prefrontal medial (implicat în interacțiunea socială complexă), sanțul drept postero-superior medial temporal, joncțiunea adiacentă temporo-parietală (cele 2 arii fiind implicate mai ales în sarcini cognitive mai simple ca : "citirea” intențiilor cuiva).

Un alt studiu care cuprinde un review al literaturii, efectuat în 2018 susține în mod similar diferența de intenționalitate între autism și schizofrenie care coexistă însă cu dificultăți similare în ceea ce priveste ToM de ordinul 1 și 2, procesarea emoțiilor și percepția socială - deși cantitativ mai marcate în autism față de schizofrenie (E Le Gall, 2018)

Studii ale biomarkerilor prin care s-a încercat identificarea unui pattern funcțional sau anatomic ce ar putea ajuta la discriminarea între ADHD și autism la copii au relevat faptul că între cele două afecțiuni există o suprapunere parțială semnificativă care contrazice separarea categoriala netă, susținută până în prezent16 (Kernbach, 2018)

În ADHD se constată existența unui deficit al funcțiilor executive ceea ce duce la o afectare a teoriei minții iar studii din ultimii 30 de ani au descris dificultățile celor cu aceasta afecțiune de a empatiza cu altii, de a recunoaște emoțiile pe față sau nuanțele prozodice în vorbire (Wilmar Pineda-Alhucema, 2018, Uekermann J, Kraemer, 2010)

În mod tradițional, medicina și psihologia îl gândesc pe celălalt ca un obiect exterior, îl cerceteaza și îl descrie, confirmând experimental ipotezele de lucru. Din perspectivă umanistă încercarea de înțelegere a realității este un demers care pornește de la început din alta poziție gândirea și percepția celuilalt este posibilă ca obiect separat doar parțial, cel care studiază și obiectul său de studiu fiind parte integrantă a aceleași realități. Întrebări de genul: Cine sunt eu? Ce face diferența dintre mine și tot ce e în jurul meu? Cum îl percep și gîndesc pe celălalt, pe mine insumi, lumea în general? - sunt esențiale în configurarea sinelui (identitatea, subiectivitatea) și a celorlalți (alteritatea) și pot fi corelate cu capacitatea de simbolizare. Simbolul reflectă eterna căutare a ceva ce se dorește a fi obiectivat fără să se reușească complet însă niciodată. Simbolizarea ne permite, prin implicarea ei în elaborarea conceptelor, sa avem referințe comune la un moment dat și intr-un context dat și permite deci, înțelegerea intențiilor celoralți făcând apel la un limbaj comun. E inclusă aici nu doar vorbirea ci și celelalte limbaje: mimico-gestual, al privirii cu sens, al tonalitații vocii și cel grafic, care asigură comunicarea și integrarea socială adecvată „practica socială este o practică simbolică” (Vintilă Mihăilescu, 5 introduceri în antropologie). Simbolizarea favorizează, în raporturile cu ceilalți, atribuirea în mod flexibil și adecvat de sensuri multiple și variate unor obiecte, situații, comportamente și cuvinte. Simbolizarea ne permite sa avem o unitate 
internă ce se păstrează în pofida diversității contextuale și chiar fiziologice cu care ne confruntăm de-a lungul vieții. Mijlocit de simbolizare, putem să fim întro relație interumană de reciprocitate firească și implicită (tacită în mare parte). Prin simbolizare, omul este capabil să fie în același timp în și în afara unui eveniment perceput (extern) sau intern și se produce un permanent dute-vino între ceea ce rămâne neconștientizat și ceea ce apare în câmpul conștiințeizo. Există o interacțiune reciprocă și o fluctuație între ceea ce e implicit și ceea ce e declarat, această interșanjabilitate, ca o oscilatie permanentă asigurată de funcția simbolizării, dă un sens lumii. Prin acest proces activ, de simbolizare, care se desfășoară între ceea ce resimțim că trăire interioară și tot ce constituie lumea exterioară este favorizată ordonarea și structurarea pshicului uman și totodată intuiția unei ordini externe.

Procesul decurge firesc în cazul majorității și nu ridică probleme deosebite decât punctual și tranzitoriu. El este însă alterat în cazul autismului, psihozei și tulburării de hiperactivitate cu deficit atențional, în care consecutiv deficitului simbolic, identitatea/alteritatea este afectată. Ceilalți sunt mai degrabă obiecte ce pot fi înțelese metodic, algoritmic, „inginerește” eventual ca un ansamblu sistematic mai mult sau mai puțin complex. În psihoza paranoidă spre exemplu sistemul e aberant deoarece e fix și îngust construit, după o logică internă ce nu permite contraargumentare iar delirul și producțiile halucinatorii functionează că ancore existențiale ce impiedică deriva generalizată. Autismul ne apare, din această perspectivă, ca o prea mare fixare în obiectual, ca o lipsă a acestei capacități de pendulare, mediată simbolic, între potență și concretizare. Obiectul rămâne același (nu sunt evocate implicit toate posibilele sensuri) indiferent de contextul spațio-temporal, celălalt nu este intuit ca un altul aflat între, se depun eforturi pentru stabilirea unei coerențe (de unde repetiția, stereotipia) și apare spaima în fața unui obiect inclasabil și care nu poate fi integrat în mod firesc intr-un sistem aflat în continuă remaniere. Deficitul de simbolizare duce la o dispersie în fragmentar, imediat, suprafață, cu aparența agitației motorii și a deficitului atențional, în lipsa coerenței asigurată de matricea invizibilă care le subîntinde. În consecință, autistul observă diversitatea dar interpretează diferența mai degraba metodic, făcând apel la logică și rezultând o interpretare rigidă, nepermeabilă la ceea ce nu poate fi gândit ci doar intuit. El se bazează în înțelegerea realității pe experiențele senzoriale asociate formal cu denumirile date obiectelor de către ceilalți și nu realizează (sau realizează deficitar, incomplet, parțial) integrarea celor două componente. Capacitatea redusă de simbolizare antrenează alterări ale raportului cu realitatea externă și internă, cu ceilați și cu sine insuși, cu consecințe în plan clinic și implicații numeroase în viața cotidiană.

După anii 50 cercetarea în psihiatria și psihologia copilului a virat spre o abordare empirică, statistică, inductivă (evidence based medicine) în defavoarea metodelor anterioare, considerate speculative. Tot mai multe studii biologice recente, aduc dovezi că ADHD, autismul și schizofrenia nu sunt entități complet distincte ci mai degrabă tulburări înrudite. Cercetările de 
cogniție socială admit medierea simbolică a cogniției și comunicării (, Ricks DM, Wing L 1975,-Ponty M, 2017) Ipoteza unei parțiale suprapuneri poate fi susținuta și prin teoretizări non-medicale sau psihologice, legate de deficite comune de structurare simbolică a psihicului în realizarea unei reprezentări coerente a lumii și a propriei persoane. Identificarea unei convergențe între cele 3 fenotipuri clinice antrenează necesitatea unor ajustări de paradigmă diagnostică și terapeutică iar cercetări ulterioare ne vor aduce clarificări suplimentare în privința acestei perspective ce se conturează în domeniul sănătății mintale și care reactualizează modalități anterioare de înțelegere a patologiei psihice.

\section{Bibliografie:}

1. American Psychiatric Association. (2013). Diagnostic and statistical manual of mental disorders (5th ed.). Washington, DC.

Ciaramidaro A, Bölte S, Schlitt S, Hainz D, Poustka F, Weber B, Bara BG, Freitag C, Walter H. Schizophrenia and autism as contrasting minds: neural evidence for the hypo-hyper-intentionality hypothesis. Schizophr Bull. 2015 Jan;41(1):171-9. doi: 10.1093/schbul/sbu124. Epub 2014 Sep 9. PMID: 25210055; PMCID: $\mathrm{PMC}_{4266299 .}$

Demontis, D., Walters, R. K., Martin, J., Mattheisen, M., Als, T. D., Agerbo, E., Baldursson, G., Belliveau, R., BybjergGrauholm, J., Bækvad-Hansen, M., Cerrato, F., Chambert, K., Churchhouse, C., Dumont, A., Eriksson, N., Gandal, M., Goldstein, J. I., Grasby, K. L., Grove, J.,
Gudmundsson, O. O., ... Neale, B. M. (2019). Discovery of the first genomewide significant risk loci for attention deficit/hyperactivity disorder. Nature genetics, $51(1)$, 63-75. https://doi.org/10.1038/s41588-0180269-7

\section{DSM History (psychiatry.org)}

Evans B. (2013). How autism became autism: The radical transformation of a central concept of child development în Britain. History of the human sciences, 26(3), 3-31. https://doi.org/10.1177/09526951134843 $\underline{20}$

Gudmundsson OO, Walters GB, Ingason A, Johansson S, Zayats T, Athanasiu L, Sonderby IE, Gustafsson O, Nawaz MS, Jonsson GF, Jonsson L, Knappskog PM, Ingvarsdottir E, Davidsdottir K, Djurovic S, Knudsen GPS, Askeland RB, Haraldsdottir GS, Baldursson G, Magnusson P, Sigurdsson E, Gudbjartsson DF, Stefansson H, Andreassen OA, Haavik J, ReichbornKjennerud T, Stefansson K. Attentiondeficit hyperactivity disorder shares copy number variant risk with schizophrenia and autism spectrum disorder. Transl Psychiatry. 2019 Oct 17;9(1):258. doi: 10.1038/s41398-0190599-y. PMID: 31624239; PMCID: PMC6797719.

IACAPAP

H.5-SCHIZOPHRENIA072012.pdf (iacapap.org)

Kernbach JM, Satterthwaite TD, Bassett DS, Smallwood J, Margulies D, Krall S, Shaw P, Varoquaux G, Thirion B, Konrad K, Bzdok D. Shared endophenotypes of default mode dsfunction în attention deficit/hyperactivity 
disorder and autism spectrum disorder. Transl Psychiatry. 2018 Jul 17;8(1):133. doi: 10.1038/s41398-018o179-6. PMID: 30018328; PMCID: PMC6050263.

Le Gall E, Iakimova G. Cognition sociale dans la schizophrénie et les troubles du spectre de l'autisme: points de convergences et différences fonctionnelles [Social cognition în schizophrenia and autism spectrum disorder: Points of convergence and functional differences]. Encephale. 2018 Dec;44(6):523-537. French. doi: 10.1016/j.encep.2018.03.004. Epub 2018 Aug 16. PMID: 30122298.

Lou HC. Paradigm shift în consciousness research: the child's self-awareness and abnormalities în autism, ADHD and schizophrenia. Acta Paediatr. 2012 Feb;101(2):112-9. doi: 10.1111/j.16512227.2011.02456.x. Epub 2011 Sep 23. PMID: 21883452

Manual de Psihiatrie a Copilului și Adolescentului, sub redactia Prof Dr Iuliana Dobrescu, Total Publishing, Volmul 1, Editia a II-a revizuita și adaugita, 2016, Bucuresti

Martinez, G., Mosconi, E., Daban-Huard, C., Parellada, M., Fananas, L., Gaillard, R., Fatjo-Vilas, M., Krebs, M. O., \& Amado, I. (2019). "A circle and a triangle dancing together": Alteration of social cognition în schizophrenia compared to autism spectrum disorders. Schizophrenia research, 210, 94-100. https://doi.org/10.1016/j.schres.2019.05.04 3

McPartland, J., \& Volkmar, F. R. (2012). Autism and related disorders. Handbook of clinical neurology, 106, $407-418$. https://doi.org/10.1016/B978-o-44452002-9.00023-1

Merleau-Ponty M. Vizibilul și invizibilul, Ed. Tact, Cluj-Napoca, 2017

Middeldorp, C. M., Hammerschlag, A. R., Ouwens, K. G., Groen-Blokhuis, M. M., Pourcain, B. S., Greven, C. U., Pappa, I., Tiesler, C., Ang, W., Nolte, I. M., VilorTejedor, N., Bacelis, J., Ebejer, J. L., Zhao, H., Davies, G. E., Ehli, E. A., Evans, D. M., Fedko, I. O., Guxens, M., Hottenga, J. J., ... Boomsma, D. I. (2016). A Genome-Wide Association MetaAnalysis of AttentionDeficit/Hyperactivity Disorder Symptoms în Population-Based Pediatric Cohorts. Journal of the American Academy of Child and Adolescent Psychiatry, 55(10), 896905.e6.

https://doi.org/10.1016/j.jaac.2016.05.0 25

Mihailescu V. Antropologie. Cinci introduceri. Ed Polirom, 2009, pp25-40 ISBN: 978-973-46-1372-4

Pineda-Alhucema W, Aristizabal E, Escudero-Cabarcas J, Acosta-López JE, Vélez JI. Executive Function and Theory of Mind în Children with ADHD: a Systematic Review. Neuropsychol Rev. 2018 Sep;28(3):341358. doi: 10.1007/s11065-018-9381-9. Epub 2018 Aug 30. PMID: 30168020.

Ricks DM, Wing L. Language, communication, and the use of symbols în normal and autistic children. J Autism Child Schizophr. 1975 Sep;5(3):191-221. doi: 10.1007/BFo1538152. PMID: 1174124. 